\title{
Perguntas em sala no ensino médio: observando o pôr do sol em um elevador panorâmico
}

\author{
Questions in high school: observing the sunset in a panoramic elevator \\ Jair Lúcio Prados Ribeiro*1 \\ ${ }^{1}$ Instituto de Química, Campus Darcy Ribeiro, Universidade de Brasília, Brasília, DF, 70910-900, Brazil
}

Recebido em 7 de Abril, 2017. Revisado em 2 de Maio, 2017. Aceito em 2 de Maio, 2017.

\begin{abstract}
O artigo apresenta uma solução algébrica e gráfica para uma pergunta elaborada por um estudante de ensino médio durante uma aula de óptica, acerca da velocidade que um elevador panorâmico deveria ter para que uma pessoa em seu interior pudesse observar o pôr do sol continuamente. Argumenta-se que perguntas que ofereçam digressões aos temas discutidos em uma aula oferecem oportunidades para a aprendizagem de ciências, na medida em que podem permitir o desenvolvimento de habilidades como teste de hipóteses, construção de modelos, raciocínio interdisciplinar e experiências de pensamento.

Palavras-chave: pôr do sol, óptica geométrica, cinemática, perguntas.
\end{abstract}

The article presents an algebraic and graphical solution to a question posed by a high school student, during an optics class, about the speed a panoramic elevator should have so that a person inside it could observe the sunset continuously. It is argued that questions that offer digressions to the topics discussed in a class offer opportunities for science learning, as they can allow the development of skills such as hypothesis testing, model building, interdisciplinary reasoning and thought experiments.

Keywords: sunset, geometrical optics, kinematics, questions.

\section{Origem do questionamento}

Na nossa experiência profissional no ensino médio, já percebemos como corriqueiro o surgimento de perguntas durante uma aula que venham a extrapolar o assunto discutido. É grande a variedade de tais questionamentos advindos dos estudantes, os quais oscilam entre explicações para observações cotidianas, detalhamentos sobre situações ou fenômenos apresentados na imprensa ou na internet e, claro, considerações hipotéticas, muitas vezes espontâneas. Essas últimas muito nos interessam, ainda que as respostas beirem impossibilidades físicas (por exemplo, objetos se movendo com velocidades superiores à luz no vácuo), pois nos obrigam, por vezes, a "pensar fora da caixa" e desenvolver uma estratégia inédita para respondê-las. O caso aqui descrito apresenta uma resposta que elaboramos para uma pergunta desse último tipo.

Durante uma aula de óptica no $2^{\circ}$ ano do ensino médio, comentamos com os estudantes sobre uma popular experiência, na qual é possível estimar o raio da Terra a partir de observações do pôr do sol [1]. O experimento envolve uma dupla observação do sol poente: inicialmente, a pessoa deve estar sentada (ou deitada) e observar o primeiro pôr do sol; assim que o astro desaparecer no horizonte, a pessoa deve se levantar, e será possível ob-

*Endereço de correspondência: jairlucio@gmail.com servar um novo pôr do sol, com um intervalo de tempo de alguns segundos entre as duas observações. Conhecido esse intervalo e o deslocamento (diferença de altura) dos olhos entre as duas observações, o raio pode então ser calculado por aplicação de regras geométricas simples.

Um estudante nos questionou então se a situação que descrevemos era similar a um trecho do popular livro infantil $O$ pequeno príncipe, de autoria do escritor francês Antoine de Saint-Exupéry [2], no qual o personagem é capaz de observar quarenta e três crepúsculos no mesmo dia enquanto corre no sentido contrário à rotação do planeta (ou asteroide) que habitava. Respondemos que não, pois no caso desse popular personagem, o deslocamento seria paralelo à superfície do planeta, enquanto no experimento que descrevemos os olhos se deslocavam transversalmente à mesma.

Nesse momento, outro estudante nos questionou então se seria possível para uma pessoa ver o Sol "parado" no horizonte "para sempre" se ela estivesse dentro de um elevador panorâmico que subisse com uma velocidade conveniente. Antes que fôssemos capazes de responder à pergunta, o estudante a complementou perguntando se tal velocidade deveria ser muito grande.

Como a pergunta era inédita, conseguimos elaborar naquele momento uma resposta apenas qualitativa: argumentamos que a velocidade provavelmente seria baixa no início (afinal, o fenômeno pode ser observado durante um 
simples levantar de uma cadeira), mas essa velocidade deveria crescer conforme a altura do observador em relação ao chão fosse incrementada. Embora consideremos que a resposta tenha sido adequada para o momento e espaço da sala de aula, sentimos a posteriori que uma resposta mais precisa para tal questionamento somente poderia advir de um tratamento algébrico, o qual é apresentado nesse curto artigo. Frisamos que apesar do questionamento ter se originado em uma aula de óptica, a resposta que desenvolvemos aqui apresenta um caráter cinemático.

Cabe ressaltar ainda que, de acordo com a revisão bibliográfica produzida por Krasilchik [3], o papel das perguntas em sala de aula é um frequente tema de investigação entre mestrandos e doutorandos em ensino de ciências. Assim, esperamos que o artigo possa apresentar alguma contribuição para pesquisadores da área, por ter se originado a partir de um questionamento oriundo de uma situação didática tradicional e se afastar da triste ideia de que um questionamento do aluno que leve a uma digressão do assunto discutido possa atrapalhar a aula ou o raciocínio do professor. Ao contrário, vemos tais questionamentos como fontes férteis de motivação e curiosidade.

Conforme o leitor perceberá, a formulação algébrica que desenvolvemos como resposta a tal questionamento vai além do ferramental matemático abordado no ensino médio, sendo sua apresentação mais adequada nas disciplinas iniciais da graduação. Assim, nas considerações finais desse texto, apresentamos algumas sugestões para o trabalho com essa pergunta (ou similares) no ensino médio.

\section{Demonstração algébrica}

A figura 1 representa um esquema da situação questionada. Na imagem, a Terra é considerada um planeta esférico de raio $r$ e período de rotação $T$, cujo centro é o ponto $O$. Na figura, o sentido dessa rotação é horário. A tangente que toca o círculo no ponto $P$ representa a trajetória dos raios de luz que, vindo do Sol, são captados pelo observador no ponto $Q$, que se encontra no elevador panorâmico à altura $h$ em relação ao solo. Os segmentos de reta $O P$ e $O Q$ formam um ângulo $\theta$ entre si, o qual é dependente do tempo. Por simplicidade, o efeito de translação do planeta ao redor do Sol é desconsiderado (ou seja, a posição do Sol é assumida como fixa em relação ao centro da Terra), assim como o desvio que a luz solar sofre devido à refração na atmosfera ou nas paredes do elevador. Assume-se ainda que o ponto inicial de movimento do elevador é o ponto $P$ e, portanto, nesse ponto, o observador deveria estar com os olhos ao nível do chão quando o pôr do sol é inicialmente visto (ou seja, origem dos tempos: $t=0$ ).

Considere então que o planeta se desloque, durante um pequeno intervalo de tempo $d t$, um pequeno ângulo $d \theta$. Nesse caso, para que o observador continue a ver o Sol no horizonte, o elevador deverá sofrer um pequeno deslocamento $d h$ (o qual é exagerado na figura para fins de legibilidade da imagem). Os movimentos combinados de rotação do planeta e ascensão do elevador levam então o observador para o ponto $S$. Isso faz com que a trajetória do elevador possa ser considerada retilínea (fig.1) em relação a um observador externo ao sistema.

$\mathrm{O}$ arco de comprimento $(r+h) d \theta$ pode ser aproximado por uma reta, pois o ângulo $d \theta$ é pequeno. Logo, os

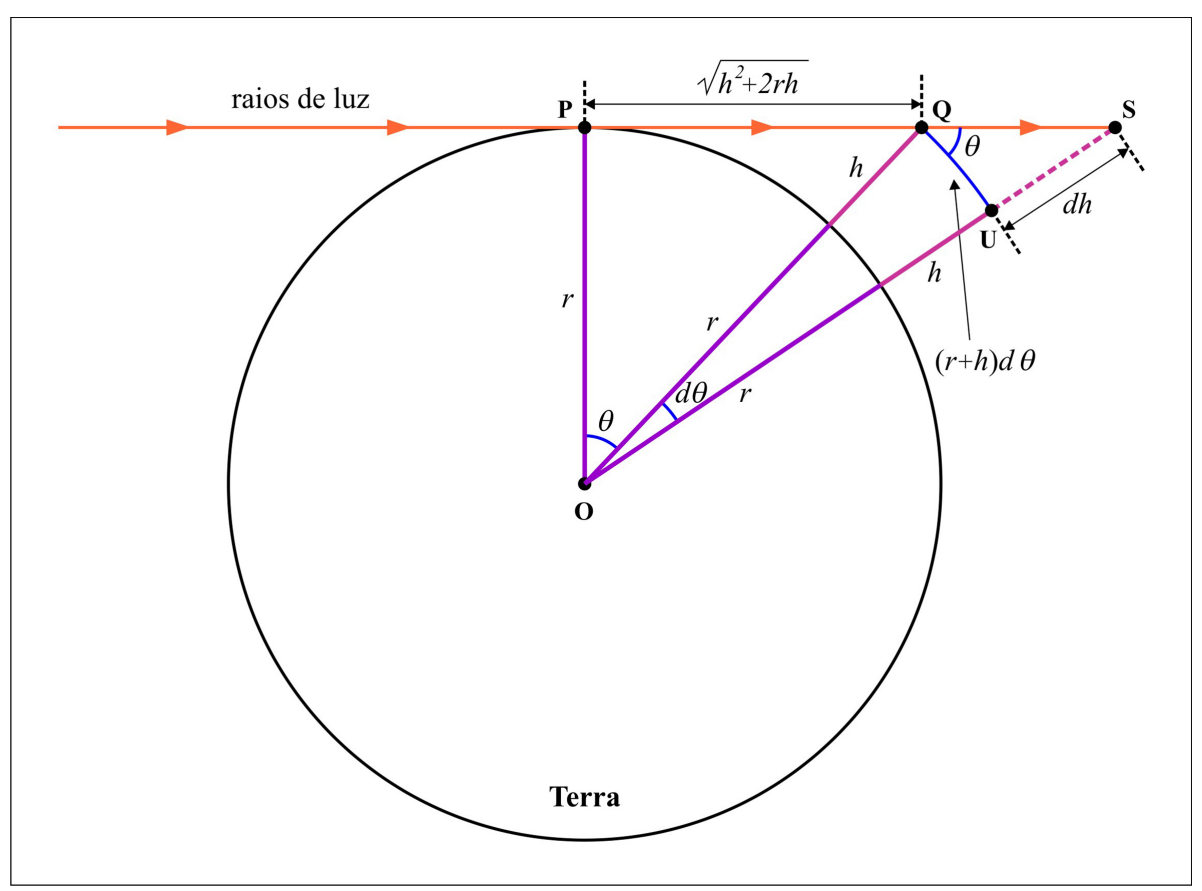

Figura 1: Representação esquemática da situação. 
triângulos $O P Q$ e $Q U S$ são semelhantes, e podemos escrever, a partir dos dados presentes na figura

$$
\frac{d h}{\sqrt{h^{2}+2 r h}}=\frac{(r+h) d \theta}{r} .
$$

A relação entre o deslocamento angular e o intervalo de tempo equivalente é

$$
\frac{d \theta}{2 \pi}=\frac{d t}{T} \rightarrow d \theta=\frac{2 \pi}{T} d t
$$

Substituindo a equação (2) na equação (1) e isolando o intervalo de tempo, temos

$$
d t=\frac{T r}{2 \pi(r+h) \sqrt{h^{2}+2 r h}} d h .
$$

Integrando-se, vem

$$
\int d t=\int \frac{T r}{2 \pi(r+h) \sqrt{h^{2}+2 r h}} d h .
$$

Pode-se considerar que os valores de $r, T$ e $h$ sejam positivos; ademais, como condição de contorno, para $t=$ 0 a altura $h$ também assumirá um valor nulo, fazendo com que a constante da integral indefinida da equação (4) seja nula. Logo, resolvendo-se a integração, vem

$$
t=\frac{\operatorname{Tarctg}\left(\sqrt{\frac{h}{2 r+h}}\right)}{\pi} .
$$

Isolando-se $h$ na equação (5), encontramos

$$
h=\frac{2 r t g^{2}\left(\frac{\pi t}{T}\right)}{1-t g^{2}\left(\frac{\pi t}{T}\right)} .
$$

A expressão acima é a função horária do movimento do elevador, sendo válida para $0 \leq t<\frac{T}{4}$, na medida em que o máximo valor do ângulo $\theta$ que em tese ainda permitiria a observação do pôr do sol nessa situação seria próximo a $\pi / 2$ radianos (ou seja, um quarto de rotação). A equação (6) é, ainda, equivalente ${ }^{1}$ a

$$
h=r\left[\sec \left(\frac{2 \pi t}{T}\right)-1\right] .
$$

Construímos então o gráfico da altura $h$ em função do tempo $t$ (fig.2). O comportamento assintótico em $T / 4$ mostra que a altura na qual o elevador deve estar para que o observador continue vendo o pôr do sol tende para um valor infinito quando o intervalo de tempo transcorrido desde a primeira observação tende para um quarto do período de rotação (seis horas). Quando é transcorrido exatamente tal intervalo de tempo, os segmentos $O P$ e $O S$ (fig.1) se tornam perpendiculares; logo, o observador está em uma linha paralela à trajetória dos raios de luz e não pode mais percebê-los ${ }^{2}$

${ }^{1}$ A equivalência entre as equações 5 e 6 é facilmente confirmada ao se plotar seus gráficos, os quais se apresentam idênticos para qualquer intervalo de tempo.

2 Como curiosidade, cita-se que no gráfico da fig.2, a altura do elevador é exatamente igual ao raio da Terra para $t=T / 6$.

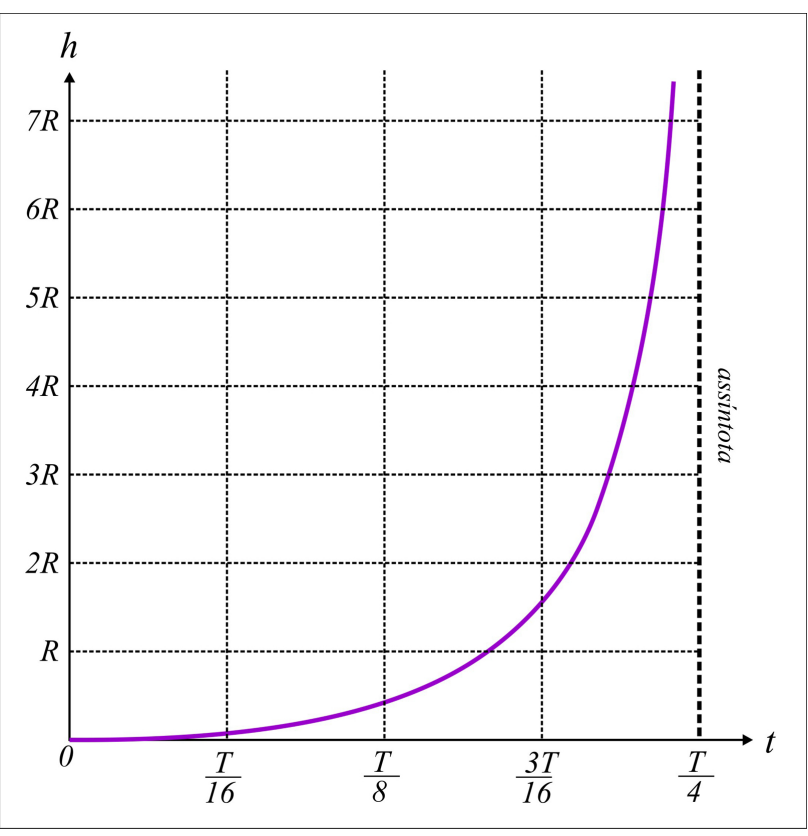

Figura 2: Gráfico da altura $h$ do elevador em função do tempo $t$, assumindo-se $0 \leq t<\frac{T}{4}$.

Para determinar a velocidade do elevador em função do tempo, deve-se derivar a equação (6) ou a equação (7), resultando em

$$
v=\frac{2 \pi r}{T} \operatorname{tg}\left(\frac{2 \pi t}{T}\right) \sec \left(\frac{2 \pi t}{T}\right) .
$$

Construímos então o gráfico da velocidade em função do tempo, para finalmente respondermos ao questionamento inicial (fig.3). Para tal, inserimos na equação (8) valores aproximados tradicionalmente usados para o raio da Terra $(r=6400 \mathrm{~km})$ e seu período de rotação $(T=$

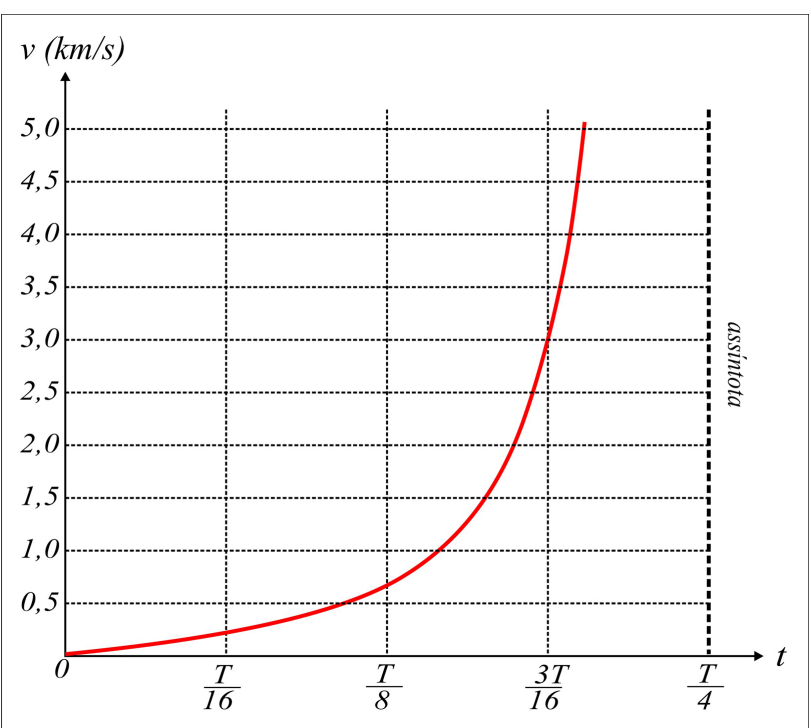

Figura 3: Gráfico da velocidade $v$ do elevador em função do tempo $t$, assumindo-se $0 \leq t<\frac{T}{4}$. 
86400 s). O gráfico gerado confirma a nossa resposta qualitativa original enunciada em sala de aula: a velocidade do elevador deve ser sempre crescente para que o Sol pareça estar "parado" para um observador no interior desse elevador. Caso a construção de tal elevador fosse tecnologicamente viável, a velocidade deveria crescer tanto que, transcorridas cerca de duas horas desde o instante inicial do movimento, ela já ultrapassaria a velocidade do som no ar $(340 \mathrm{~m} / \mathrm{s})$.

A velocidade de um corpo, como sabemos, apresenta limitações físicas: o elevador não poderia ter velocidade infinita (para $t=T / 4$ ), pois ele não seria capaz de ultrapassar a velocidade da luz no vácuo $\left(c=3.10^{8}\right.$ $\mathrm{m} / \mathrm{s}$ ) Esse limite, a partir da fig.3 e da equação (8), seria atingido quando restassem cerca de dezessete segundos para se completar um quarto de rotação. Um movimento em velocidade tão alta exigiria o uso da relatividade geral (pois o elevador possui aceleração) para ser explicado a contento, pois a dilatação do tempo deveria ser levada em conta. Não adentraremos tal seara nesse artigo.

Se nos limitarmos à mecânica clássica, vale ressaltar que as grandes velocidades e altitudes que o observador deveria atingir para continuar vendo o pôr do sol de forma contínua ultrapassam sobremaneira as apresentadas por elevadores panorâmicos atuais. A título de comparação, a máquina desse tipo que atinge a maior altitude em relação ao solo é o elevador Bailong ${ }^{3}$, aberto ao público em 2002, o qual foi construído em um penhasco do sítio histórico Wulingyuan, na China. O elevador em questão é capaz de percorrer os 326 metros de sua ascensão em aproximadamente dois minutos [4], com velocidade média de aproximadamente $2,7 \mathrm{~m} / \mathrm{s}$. O elevador mais rápido do mundo, no edifício Taipei 101, em Taiwan, atinge velocidades superiores a $16 \mathrm{~m} / \mathrm{s}$ [5]. Assim, ampliamos o gráfico da altura (fig.4) e da velocidade (fig.5) para investigar o movimento desse elevador hipotético em alturas bastante inferiores ao raio da Terra $(h<<r)$.

Fazendo tal consideração, os gráficos apontam que o movimento do elevador não apresentaria velocidades surreais, devendo atingir $8,1 \mathrm{~m} / \mathrm{s}$ após quatro minutos de movimento (tal valor é tecnologicamente possível, conforme os dados do parágrafo anterior apontam). É interessante perceber também que, para tal intervalo de tempo ( $t \leq 4,0 \mathrm{~min}$ ), os gráficos mostram que o elevador deveria ter um movimento com aceleração constante (isto é, uniformemente variado), pois a velocidade cresce de forma aproximadamente linear.

Tal resultado nos agrada, pois o movimento uniformemente variado é um clássico tema de estudo nas aulas de física do ensino médio. A álgebra da demonstração formal, portanto, pode ser bastante simplificada, ainda que a apresentação dos passos intermediários ainda não seja adequada para o ensino médio. Assumindo-se $h<<r$,

\footnotetext{
$\overline{3}$ A tradução literal é "Elevador dos Cem Dragões".
}

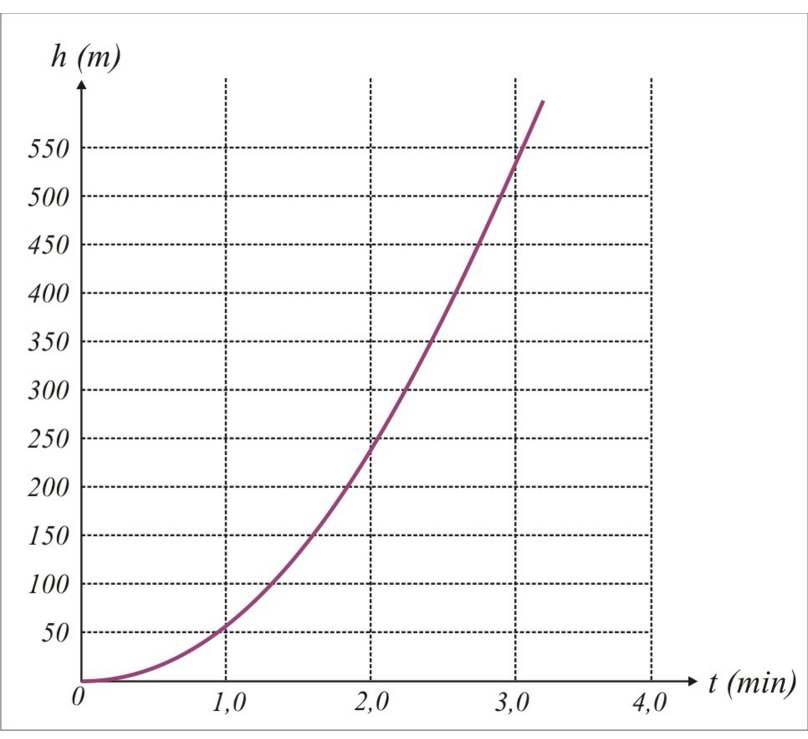

Figura 4: Gráfico da altura $h$ do elevador em função do tempo $t$, considerando-se $h \ll r$.

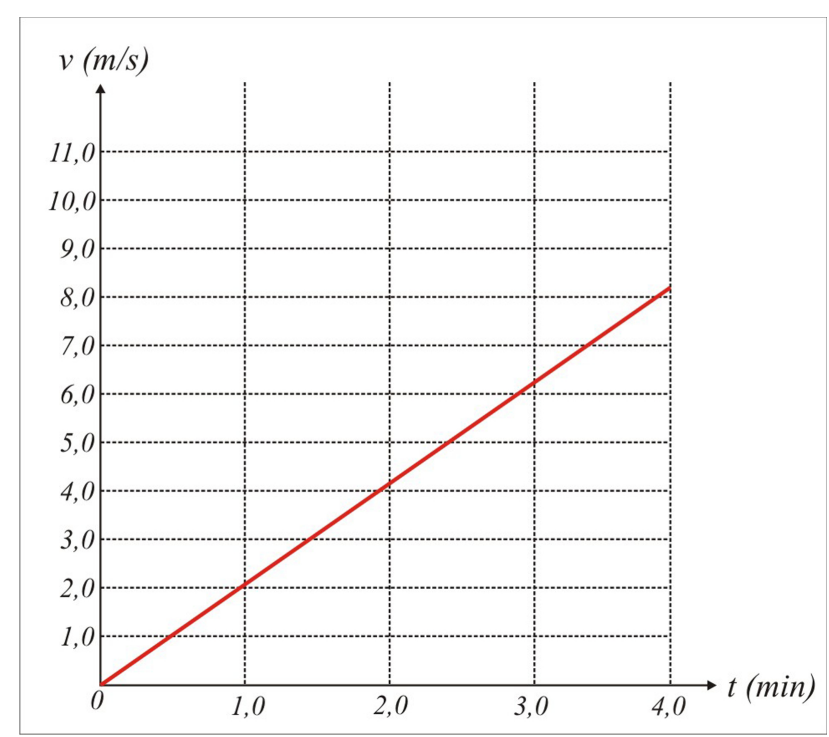

Figura 5: Gráfico da velocidade $v$ do elevador em função do tempo $t$, considerando-se $h \ll r$.

a equação (1) pode ser reescrita ${ }^{4}$ na forma

$$
\frac{d h}{\sqrt{2 r h}}=d \theta
$$

Substituindo-se a equação (2) na equação (9) e integrandose o resultado, a nova função horária dos espaços é dada por

$$
h=\frac{2 \pi^{2} r}{T^{2}} t^{2} .
$$

A forma quadrática da equação 10 é característica de um movimento uniformemente variado. A velocidade,

\footnotetext{
${ }^{4}$ Essa consideração faz com que $\frac{r+h}{r} \rightarrow 1$ e $\sqrt{h^{2}+2 r h} \rightarrow \sqrt{2 r h}$, levando à simplificação da equação 1 .
} 
portanto, apresentaria uma variação linear com o tempo, na forma

$$
v=\frac{4 \pi^{2} r}{T^{2}} t
$$

Substituindo-se os valores tradicionais de $r$ e $T$ na equação (11), encontramos como coeficiente linear (ou seja, a aceleração do elevador em seus momentos iniciais) o valor de $0,034 \mathrm{~m} / \mathrm{s}^{2}$, o qual coincide com o coeficiente linear do gráfico apresentado na fig.5. É interessante perceber, finalmente, que essa aceleração depende apenas de dois fatores: o raio do planeta e o seu período de rotação.

\section{Considerações finais}

Ainda que uma pergunta em sala de aula possa ter caráter especulativo, acreditamos que o professor deve buscar tratá-la com seriedade, se o tempo e o espaço escolar assim o permitirem. Afinal, a busca por respostas a tais perguntas pode incentivar nos alunos o desejo pela descoberta, a curiosidade e a imaginação, condições que favorecem a aprendizagem.

Cabe ressaltar que perguntas sobre ciência de caráter hipotético, ficcional ou absurdo não existem apenas em situações de sala de aula. Um conjunto interessante de exemplos de tais questionamentos pode ser encontrado no livro What if ? [6], elaborado pelo quadrinista Randall Munroe, no qual são apresentadas respostas científicas sérias para questões similares à descrita nesse artigo, tais como o que aconteceria se um secador de cabelo ligado fosse colocado em um cubo hermeticamente fechado, qual seria o destino da Terra se o Sol subitamente desaparecesse ou qual a dose letal de neutrinos para seres humanos. A similaridade com questões que já ouvimos em sala é completa: em aulas de relatividade, os estudantes usualmente desejam saber o que ou se é possível voltar no tempo ao se mover mais rápido do que a luz, ou em aulas de termologia, se uma geladeira aberta pode funcionar como ar condicionado. A formulação de respostas para tais perguntas exige interpretações apoiadas em princípios científicos e pode, em nossa opinião, estimular a aprendizagem de tais princípios, por mostrar a validade de sua aplicação mesmo em situações hipotéticas

No caso aqui relatado, a pergunta ficcional exigiu, para a elaboração de sua resposta, atividades de pesquisa (por exemplo, os valores reais de velocidades em elevadores, o raio da Terra, etc.), raciocínio algébrico (conforme demonstrado pelas equações presentes nesse artigo), testes de hipóteses (a consideração de uma situação geral em contraste com uma aproximada), construção de modelos (no caso, a fig.1), adoção de condições simplificadoras ao se tratar com uma situação complexa, raciocínio interdisciplinar (um questionamento em uma aula de óptica exige uma resposta advinda da cinemática) e um teste experimental através de uma "experiência de pensamento", na medida em que a construção de tal elevador não é provável. Poder-se-ia até mesmo construir um modelo experimental em escala reduzida da situação para se testar a validade das equações desenvolvidas. Todas essas habilidades são desejáveis não apenas na atividade científica em si, mas também no ensino das disciplinas de ciências.

Percebemos, durante a elaboração desse artigo, diversas possibilidades para sua abordagem em sala de aula no ensino médio. A situação poderia servir como um exemplo dramático de composição de movimentos; os estudantes poderiam ser estimulados a fazer experiências de pensamento que os levassem a perceber os fatores que influenciariam na velocidade e aceleração do elevador; poder-se-ia trabalhar de forma qualitativa, construindose o gráfico da altura em função do tempo (fig.2) a partir de modificações sucessivas na fig.1; o caso geral do movimento do elevador poderia ser comparado com situações de lançamento de foguetes; poder-se-ia demandar que os estudantes construíssem um modelo geométrico da situação hipotética e investigar quais condições de simplificação eles teriam assumido em tal construção, implícita ou explicitamente; e, por fim, acreditamos que seria possível ainda verificar se elevadores panorâmicos reais poderiam ser usados para tais observações, em um trabalho de pesquisa estimulada para proposta de soluções para o questionamento inicial.

\section{Referências}

[1] DarylScience's E-World Measure the Earth's Radius with a Nothing But a Stopwatch and Meter Stick! disponível em http://www.darylscience.com/downloads/ DblSunset.pdf acesso em 06/04/2017.

[2] A. Saint-Exupéry, Le Petit Prince (Harcourt Inc., Paris, 2001), 1 ${ }^{\mathrm{a}}$ ed., 85 p.

[3] M. Krasilchik, São Paulo em Perspectiva 14, 85 (2000).

[4] E. Nilsson, China Daily - Peak attractions, disponível em http://www.chinadaily.com.cn/cndy/2007-10/ 17/content_6181812.htm, acesso em 07/04/2017.

[5] Business Insider, Asian Skyscrapers Dominate a New List of the World's Fastest Elevators, disponível em http://www.businessinsider.com/the-8-fastestelevators-in-the-world-2013-1\#1-taipei-101-taipei-taiwan-8, acesso em 07/04/2017.

[6] R. Munroe, What if? Serious Scientific Answers to Absurd Hypothetical Questions (Houghton Mifflin Harcourt, Boston, 2014), $1^{\mathrm{a}}$ ed., 359 p. 